\title{
Evaluation of the safety, tolerance and efficacy of 1-year consumption of infant formula supplemented with Lactobacillus fermentum CECT5716 LC40 or Bifidobacterium breve CECT7263: a randomized controlled trial
}

J. Maldonado 1,2,3,4 , M. Gil-Campos ${ }^{5,6}$, J. A. Maldonado-Lobón7, M. R. Benavides ${ }^{8}$, K. Flores-Rojas ${ }^{5}$, R. Jaldo9 I. Jiménez del Barco ${ }^{10}$, V. Bolívar ${ }^{9}$, A. D. Valero ${ }^{7}$, E. Prados ${ }^{9}$, I. Peñalver ${ }^{9}$ and M. Olivares ${ }^{7 *}$ (I)

\begin{abstract}
Background: The microorganism present in breast milk, added to other factors, determine the colonization of infants. The objective of the present study is to evaluate the safety, tolerance and effects of the consumption of a milk formula during the first year of life that is supplemented with L. fermentum CECT5716 or Bifidobacterium breve CECT7263, two strains originally isolated from breast milk.

Methods: A randomized, double blind, controlled, parallel group study including healthy, formula-fed infants was conducted. Two hundred and thirty-six 1-month-old infants were selected and randomly divided into three study groups according to a randomization list. Infants in the control group received a standard powdered infant formula until 12 months of age. Infants in the probiotic groups received the same infant formula but supplemented with $L$. fermentum CECT5716 LC40 or B. breve CECT7263. Main outcome was weigh-gain of infants as safety marker.

Results: One hundred and eighty-nine infants completed the eleven months of intervention (61 in control group, 65 in Lf group and 63 in Bb group). The growth of infants in the three groups was consistent with standards. No significant differences were observed in the main outcome, weight-gain (Control group: $5.77 \mathrm{Kg} \pm$ 0.95, Lf group: $5.77 \mathrm{Kg} \pm 1.31, \mathrm{Bb}$ group: $5.58 \mathrm{Kg} \pm 1.10 ; p=0.527)$. The three milk formulae were well tolerated, and no adverse effects were related to the consumption of any of the formula. Infants receiving B. breve CECT7263 had a 1.7 times lower risk of crying than the control group $(\mathrm{OR}=0.569, \mathrm{Cl} 95 \% 0.568-0.571 ; p=0.001)$. On the other hand, the incidence of diarrhoea in infants receiving the formula supplemented with L. fermentum CECT5716 was a 44\% lower than in infants receiving the control formula $(p=0.014)$. The consumption of this Lactobacillus strain also reduced the duration of diarrhoea by 2.5 days versus control group $(p=0.044)$.
\end{abstract}

Conclusions: The addition of L. fermentum CECT5716 LC40 or B. breve CECT7263, two probiotic strains naturally found in breast milk, to infant formulae is safe and induces beneficial effects on the health of infants.

Trial registration: The trial was retrospectively registered in the US Library of Medicine (www.clinicaltrial.gov) with the number NCT03204630. Registered 11 August 2016.

Keywords: Infant formula, Probiotics, Safety, Diarrhoea, Colic

\footnotetext{
* Correspondence: molivares@biosearchlife.com

${ }^{7}$ Biosearch Life, Research Department, Granada, Spain

Full list of author information is available at the end of the article
}

(c) The Author(s). 2019 Open Access This article is distributed under the terms of the Creative Commons Attribution 4.0 International License (http://creativecommons.org/licenses/by/4.0/), which permits unrestricted use, distribution, and reproduction in any medium, provided you give appropriate credit to the original author(s) and the source, provide a link to the Creative Commons license, and indicate if changes were made. The Creative Commons Public Domain Dedication waiver (http://creativecommons.org/publicdomain/zero/1.0/) applies to the data made available in this article, unless otherwise stated. 


\section{Background}

Breast milk contains physiological microbiota, which contributes to colonization in infants $[1,2]$. The microorganisms present in breast milk, as well as the prebiotic factors included in it, determine the colonization of infants and contribute to the differences found between the microbiota of formula-fed and breast-fed infants [3]. Correct, early colonization is a key factor in the process of maturation of infants during the first months [4]. In this sense, studies showing that the first contact with microorganisms triggers a cascade of reactions that are crucial for infant immune system maturation have been particularly relevant $[5,6]$. In fact, exposition to microbial dysbiosis early in life has been associated with diseases related to the dysfunction of the immune response, such as allergies [7, 8], type 1 diabetes [9], celiac disease [10] and inflammatory bowel disease [11]. Because of the importance of early colonization on the future health of infants, several strategies to modulate infant colonization are being used in infant nutrition. One of these strategies is the supplementation of infant formula with probiotic microorganisms and prebiotic factors, such as galacto oligosaccharides.

In this context, the use, in infant formula, of bacterial strains originally found in the breast milk of healthy women seems to be a coherent strategy to supply to the formula-fed infants with microorganisms that are naturally provided to breast-fed infants. In line with this strategy, two clinical trials were previously performed in infants with Lactobacillus fermentum CECT5716, a probiotic strain originally isolated from breast milk. The studies demonstrated the safety of the probiotic strain, even long term $[12,13]$. Moreover, the administration of the strain was associated with a lower incidence of gastrointestinal infections in the infants during the period of intervention, which was corroborated in the two clinical trials performed in the infant population $[12,14]$.

While it is true that Lactobacillus is a common inhabitant in an infant's intestine, the genus Bifidobacterium is one of the most abundant, especially in breast-fed infants $[15,16]$. Bifidobacterium has been associated with beneficial effects on immune and intestinal function [17, 18]. Since Bifidobacterium spp are also found in breast milk, the addition of Bifidobacterium strains to infant formula adheres to the strategy to supply formula-fed infants with strains naturally found in breast milk.

To date, a large number of studies have been carried out in this field with very positive results for some of the strains analysed. However, experts still think that more evidence is needed $[19,20]$. The objective of the present study is to evaluate the safety, tolerance and effects of the consumption of milk formula supplemented with strains originally isolated from breast milk, L. fermentum
CECT5716 or Bifidobacterium breve CECT7263, during the first year of life.

\section{Methods \\ Study design and medical centers}

This is a randomized, double blind, controlled, parallel study with three groups developed in the Paediatrics department of two Spanish hospitals, Hospital Virgen de las Nieves (Granada, Spain) and Hospital Reina Sofía (Córdoba, Spain), two private paediatric clinics (Roquetas de Mar, Almería (Spain) and "Cristo de la Salud", Granada (Spain)), and 7 public paediatric health centers (Andalusian Health Service, Granada (Spain)).The study adheres to CONSORT guidelines and was retrospectively registered in the US Library of Medicine (www. clinicaltrial.gov) with the number NCT03204630.

\section{Participants and criteria of inclusion}

Healthy infants one-month of age who were exclusively feeding with infant formula were included in the study after the parents or caregivers gave written consent. Subjects were excluded from the study if they had a history of mild or serious gastrointestinal disorders (gastroesophageal reflux, history of chronic diarrhoea or constipation), gastrointestinal surgery, metabolic disorders (lactose intolerance, diabetes), cow's milk protein allergy, immune deficiency, antibiotic prescription one-week before inclusion and prior use of probiotic-containinginfant formula.

\section{Sample size calculation}

The variable for the calculation of the sample size was the primary outcome, which was the average weight gain of infants between baseline and $120 \pm 3$ days of age. Taking into account several safety studies in which growth was considered the primary outcome $[21,22]$ and in accordance with the Scientific Committee for Food Report, the study was designed to have power to detect a difference in weight gain equal to 0.5 standard deviations [23]. Therefore, it was calculated that 63 children would be required in each formula group with a significance level of $5 \%$ and a power of $80 \%$ (two-sided test). In order to compensate for drop outs during the intervention, the sample size was increased by $25 \%$. Statistical computations in $\mathrm{R}$ was performed to calculate sample size needed to test interactions: One formulation was based on the formula proposed per Lu et al. [24] for analysing repeated measures with missing data, and for the 5\% level, $80 \%$ power and progressively missing $20 \%$ of responses and the total sample size per treated group of 76 participants were needed (library longpower from R). The second calculation was performed regarding the sample sized need for obtaining regression coefficients in multiple regression [25]. The implementation of the 
calculation was performed in R using the library MBESS, and the results obtained was a total of 34 participant per regression coefficient.

\section{Randomization and blinding}

Infants included in the study were randomly allocated into three study groups by using the computer program $\left(\mathrm{SIGESMU}^{\circ}\right)$. According to the randomization list each recruiter center received batches of infant formula labelled with the corresponding numbers. Each volunteer received in each visit a batch of infant formula contained enough formula for the next 3 months until the next paediatrician visit. The infant formulae were supplied by Lactalis-Puleva (Granada, Spain) in indistinguishable plain white tins. The blinding of the trial was ensured by a sensorial test of the three formulas by an expert panel that concluded the three products were identical. Paediatricians, parents and researchers only knew the volunteer's code, not knowing which group belonged. The list of randomization was revealed once the study was completed and the code of each group once the statistical analysis of the data was performed.

\section{Products of the study and guidelines of consumption}

The control formula was a standard powdered infant formula with a nutritional composition in accordance with current EU regulations for both starter and follow-on formula. Probiotic groups received the same formula but supplemented with L. fermentum CECT5716 Lc40 in case of Lf group or B. breve CECT7263 in case of Bb group. In both cases the concentration dose of probiotic strain was $10^{7} \mathrm{cfu} /$ $\mathrm{g}$ The concentration of the probiotic in the formula was analysed and confirmed every 6 months. Formulae were consumed by the infants from 1 month of age until the age of 12 months (intervention period). The paediatricians prescribed the amounts of formula per day to be administered to the infants and the guidelines for complementary feeding according to current ESPGHAN guidelines [26].

\section{Study outcomes and data collection}

Average weight gain between baseline (1 month of age) and 4 months of age was the primary outcome of the study. Secondary outcomes included average weight, length and head circumference, incidence of intestinal infections, feeding-related behaviour, adverse effects associated with formula consumption and faecal microbiota. The follow-up visits to the paediatrician were performed at baseline and at the ages of 2, 4, 6, 9 and 12 months.

The paediatrician made the diagnosis of infectious diseases according to specific symptoms and standardized definitions. Gastrointestinal infection was characterized by occurrence of loose or watery stool $\geq 3$ times/day with or without a fever or vomiting [27], and respiratory tract infections were determined in case of presence of abundant mucosity and/or cough during two or more days in a row with or without a fever or the presence of wheezing and/ or crepitant with or without fever. Parents received a diary to collect data about incidences in the health of the infants and unscheduled visits with a doctor. Moreover, they received a notebook with questionnaires to be completed every two weeks, in which information regarding the daily number of depositions, behaviour and gastrointestinal discomfort were recorded (Table 1).

Four faecal samples were collected simultaneously from every infant at baseline and 4, 6, 9 and 12 months of age, maintained at $-20^{\circ} \mathrm{C}$ and processed within 4-weeks. Of the four samples, three were used for parameters determination, and the last one was stored at $-80^{\circ} \mathrm{C}$.

\section{Faecal bacteria quantification}

Lactobacillus spp., Bifidobacterium spp., Clostridium spp., Bacteroides spp. and Escherichia coli counts were measured by quantitative polymerase chain reaction.

The ATP $^{\text {ma }}$ GENOMIC DNA MINI KIT (TISSUE) AGT300 (ATP Biotech Inc., Taipei City 10,683, Taiwan)

Table 1 Feeding related parameters

\author{
During the last 2 days the number of fecal depositions/day \\ During the las 2 days the feces color was \\ During the last 2 days the consistency of feces was \\ During the last 2 days the infant suffered flatulency \\ During the last 2 days the infant suffered regurgitation
}

During the past 2 days the total sum of sleeping hours in $24 \mathrm{~h}$ was on average

Gender Temper: The infant's behavior when awake during the last 2 days is best described as

Colic symptoms: during the last 2 days the infant has suffered continuous and disconsolate crying episodes

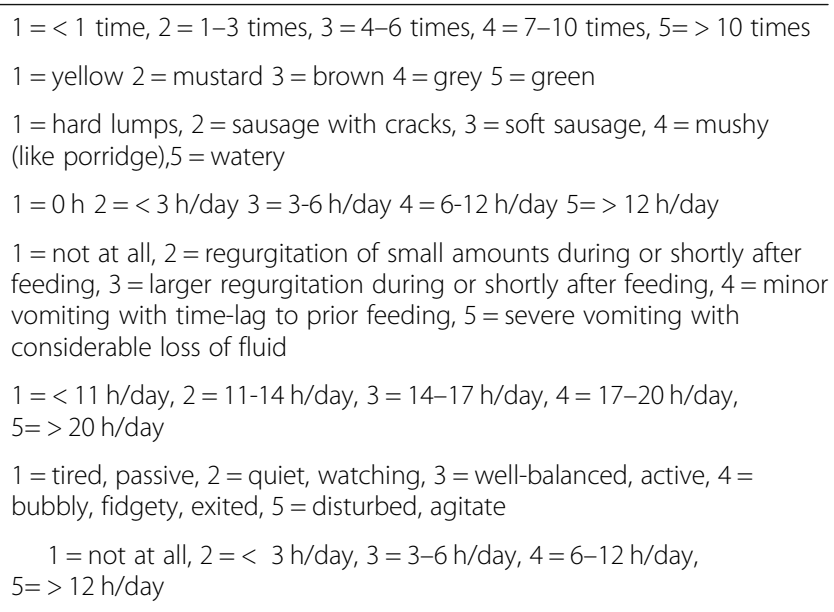


was used for bacterial DNA isolation. In brief, the colonic content was homogenized in Peptone Water at a concentration of $100 \mathrm{mg} / \mathrm{ml}$ under sterile conditions, and $200 \mu \mathrm{l}$ of the previous suspension was added to an Eppendorf tube $(20 \mathrm{mg} / \mathrm{ml})$ for DNA extraction following the instructions of the ATP ${ }^{\mathrm{ma}}$ GENOMIC DNA MINI KIT (TISSUE) AGT300 protocol.

DNA quantification was performed by qPCR using $\mathrm{SYBR}^{\circ}$ green as a fluorophore (Quantifast SYBR Green OCR Kit Qiagen Cat. No 204057) and specific primers for each group as previously described by MaldonadoLobón et al. [13].

\section{Statistical analysis}

Descriptive analysis and bivariate statistical tests per treatment group were performed for baseline characteristics as well as the outcomes. For this analysis, when data were continuous and normality could be assumed, ANOVA was performed using $\mathrm{F}$ when data were homogeneous and Welch when equal variances could not be assumed. Categorical variable percentages were calculated, and differences between groups were analysed using the chi-square test or the chisquare exact test in the case of large contingency tables without enough cases by cells of categories. For the outcomes related to an event, the Incidence Rate Ratio (IRR) and Odd Ratio (OR) were calculated.

Statistical models were applied in order to analyse the differences in the responses between treatment groups adjusted by other covariates and factors that may be associated to the change of the responses. The statistical models applied to the primary and secondary outcomes were adjusted by time, age at entry, group of treatment, sex, C-section, having siblings, rotavirus vaccination, breastfeeding prior to intervention and gestational age. Linear Mixed Models were applied for continuous data when the residuals were normally distributed. Poisson Mixed Models were applied when the data recorded were related to the number of events observed, and Logistic Mixed Models were applied when the outcomes to be analysed were binary responses.

Ordinal logistic regression mixed models were applied to the responses of secondary outcomes over time and adjusted by relevant covariates. Ordinal outcomes were, for example, stool frequency, consistency, colic and flatulence, regurgitation symptoms and sleeping hours. Additionally, a multinomial logistic regression mixed model was applied for nominal data, such as faeces colour.

The statistical software used to perform the analysis was $R$ version 3.1. Statistical tests at the 5\% significance level (two-tailed) were considered for hypothesis testing.

\section{Results}

Population

Two hundred and thirty-six infants were included in the study and randomized between April 2011 and July 2012. The intervention ended on June 2013. A flow chart of participants is shown in Fig. 1. Nineteen percent of the infants did not complete the intervention and withdrew from the study. Causes of withdrawal were the perception by the mother that the child did not drink enough milk, changes to another kind of formula because of a cow milk allergy, lactose intolerance, infant colic, reflux or constipation. Two additional infants were excluded because they received a commercial formula and another two infants mistakenly received the formula corresponding to another group of the study. No differences among the groups were detected between the number and causes of withdrawal. The data of all the infants included in the study were analysed (analysis per intention to treat, ITT). For the analysis of Incidence Rate Ratio, in which events accumulated during the 11 months of intervention, only data of infants who completed the intervention were taken into account (per protocol). If statistically significant differences were observed, a second analysis was performed including data of all infants in the study (ITT analysis). In this case, 189 infants who completed the intervention were included in the analysis.

The baseline characteristics of the 236 infants included in the study were analysed. In addition to those related to the infants, they were included mother's characteristics, variables related to gestation and delivery, and the environment around the infant. All these baseline characteristics were comparable among the study groups (Table 2).

\section{Growth of infants}

Based on the mean weight, length and head circumference for boys and girls, the corresponding mean for each group over time was represented with respect to the standard percentile curves (Fig. 2). Growth curves for weight, length and head circumference were very similar in the three groups. With respect to weight, values for the three groups remained quite close to one another, around the $50 \%$ percentile, until 6 months. After 6 months, the means were between the 50 th and 75 th percentiles. Similar results were observed for the growth curves of length and head circumference.

Mean weight, length and head circumference for each group were obtained at 1, 2, 4, 6, 9 and 12 months (Table 3). Regarding weight, no significant differences were observed among the groups at any time. To analyse the overall effect, the linear mixed model was adjusted by basal characteristics. The model did not show 


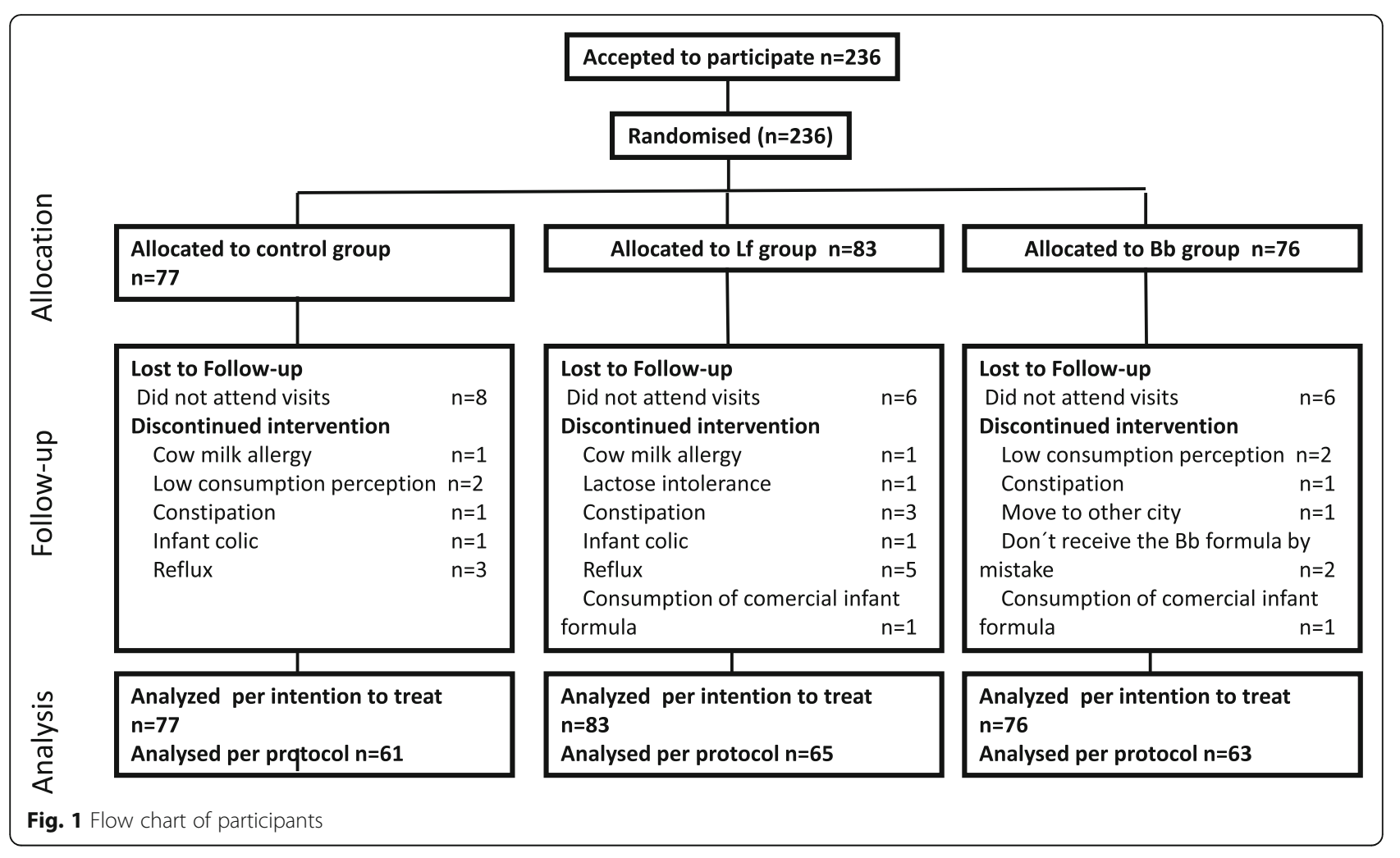

significant differences between groups ( $p=0.427$ (Lf vs Control); $p=0.296$ (Bb vs Control)). Moreover, no significant differences were detected in the primary outcome, mean weight gain from 1 to 4 months of age (Control group: $2.67 \pm 0.70 \mathrm{Kg}$; CI $95 \%$ 2.50-2.82, Lf group: $2.79 \pm 0.79 \mathrm{Kg}$; CI 95\% 2.60-2.98, Bb group: $2.76 \pm 0.71 \mathrm{Kg} ;$ CI 95\% 2.58-2.93; $p=0.560$ ). Mean weight gain from 1 to 12 months was also analysed and no significant differences among the groups were observed (Control group: $5.77 \pm 0.95 \mathrm{Kg}$ CI $95 \% 5.53-$ 6.01, Lf group: $5.77 \pm 1.31 \mathrm{Kg}$; CI $95 \% 5.44-6.10, \mathrm{Bb}$ group: $5.58 \pm 1.10 \mathrm{Kg}$; CI 95\% 5.31-5.85; $p=0.527$ ).

The length of the children was similar throughout the study among the 3 groups. However, at 4 months, infants in the Lf group showed having slightly longer length measurements than those of the control group $(p=0.049)$. This difference was primarily observed in boys $(p=0.021)$. The estimated parameters from the

Table 2 Baseline characteristics of the subjects that participated in the study

\begin{tabular}{llll}
\hline & CG & Lf & Bb \\
$(n=77)$ & $(n=83)$ & $76)$ & $39 / 37(51.3 / 48.7)$ \\
\hline Male/female, $n$ (\%) & $41 / 36(53.2 / 46.8)$ & $48 / 35(57.8 / 42.2)$ & $3.75 \pm 1.19$ \\
Age at enrolment (weeks), mean \pm SD & $3.73 \pm 0.93$ & $3.80 \pm 1.11$ & $3.17 \pm 0.59$ \\
Birth weight (kg), mean \pm SD & $3.21 \pm 0.5$ & $3.18 \pm 0.4$ & 32.9 \\
Delivery by cesarean (\%) & 27.3 & 26.5 & $38.9 .2 \pm 1.7$ \\
Gestational age (weeks) mean \pm SD & $39.0 \pm 1.5$ & $39.2 \pm 1.3$ & $33.93 \pm 1.7$ \\
Age of mother at birth (years) mean \pm SD & $34.41 \pm 2.3$ & $34.06 \pm 1.3$ & $5.25 \pm 8.9$ \\
Breast feeding (days) mean \pm SD & $6.13 \pm 9.6$ & $4.06 \pm 7.8$ & 19.2 \\
Smoking during pregnancy (\%) & 16.7 & 14.5 & 12.2 \\
Smoking during lactacion (\%) & 15.6 & 38.6 & 17.9 \\
Smoking in the household (\%) & 42.9 & 50.6 & 48.7 \\
Older siblings (\%) & 61.5 & $69.8 \pm 14.2$ & 51.3 \\
Weight of mother (kg) mean \pm SD & $70.8 \pm 13.95$ & 32.5 & $70.7 \pm 14.1$ \\
Pets at home (\%) & 26.0 & & 42.1 \\
\hline
\end{tabular}




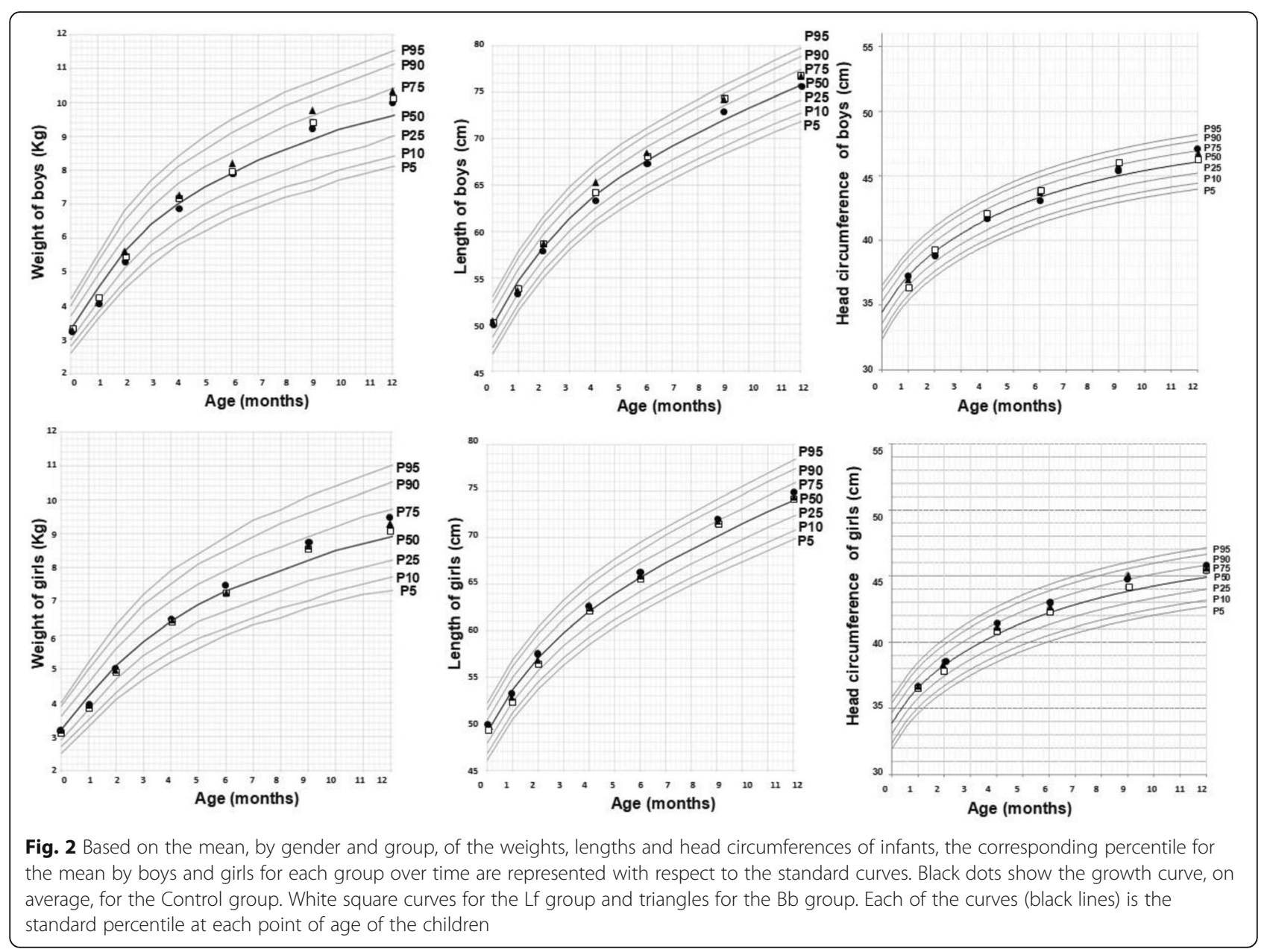

linear mixed model showed no differences for length among experimental groups ( $p=0.588$ (Lf vs Control), $p=0.475$ (Bb vs Control)). Interestingly, a difference in behaviour or length responses of infants born by $\mathrm{C}$ section was observed depending on the group. In the Control group, infants born by $\mathrm{C}$-section had a lower length than infants born by natural delivery $(p=0.042)$. However, in the Lf and Bb groups, infants born by $\mathrm{C}$ section had higher length responses than infants born by natural delivery ( $p=0.006$ for Lf group and $p=0.018$ for Bb group).

Finally, no differences were observed in head circumference values among groups $(p=0.384$ (Lf vs Control; $p=0.183(\mathrm{Bb}$ vs Control)).

\section{Formula intake, tolerance and adverse effects}

No significant differences were found among the study groups in regard to daily intake of formula (Table 4). The daily consumption of the formula corresponded to an average dosage of probiotic bacteria of $1 \times 10^{9} \mathrm{cfu} /$ day up to 6 months and $7-8 \times 10^{8} \mathrm{cfu} /$ day between 6 and 12 months.
No adverse effects associated to supplementation with L. fermentum CECT5716 and B. breve CECT7263 were detected during the study.

Some withdrawals were related to symptoms which might have been related to the tolerance of the formula, such as reflux, infant colic, constipation or low consumption of the formula (Fig. 1). However, no significant differences in the dropout rates among groups were detected and incidences were in line or even below that those in general population; therefore, symptoms could not be related to the supplementation with $L$. fermentum CECT5716 or B. breve CECT7263 and paediatricians considered three formula of the study well tolerated.

Parameters related to tolerance and intestinal function were also evaluated based on the questionnaire explained in methods section (Table 1).

Faecal depositions: most of the infants showed a stool frequency of 1-3 depositions per day. In general, the probability of an infant to have 1-3 faecal depositions/ day is 0.945 ; in contrast, the probability of having a frequency of less than once a day is 0.095. Differences among the groups were observed during the first month 


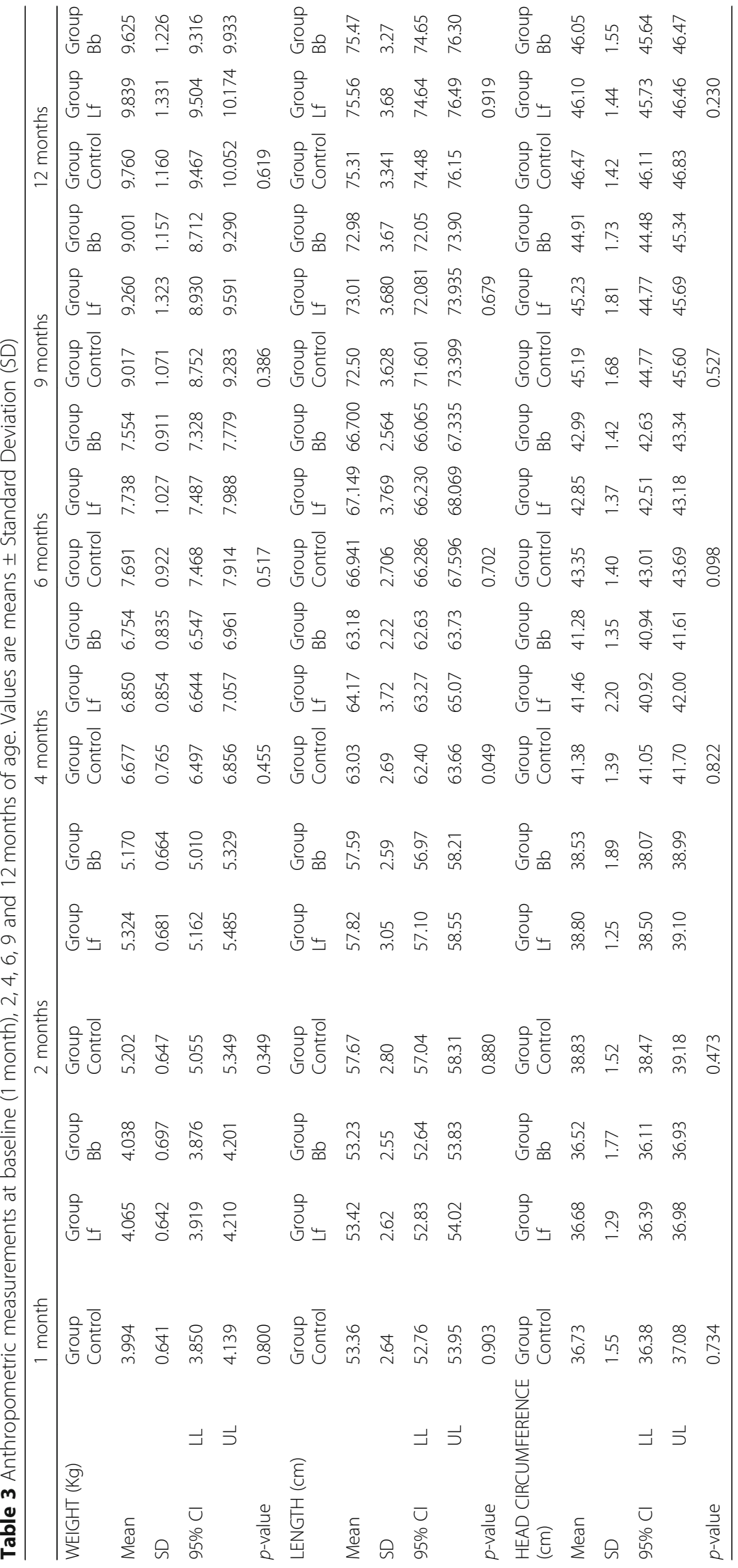


Table 4 Formula intake corresponding to amount of milk $(\mathrm{mL})$ reported by parents to be consumed by the infants for each time is showed

\begin{tabular}{lllllll}
\hline INTAKE FORMULA-FED $(\mathrm{mL})$ & & 2 months & 4 months & 6 months & 9 months & 12 months \\
\hline Control group & Mean & 783.659 & 883.784 & 730.290 & 618.750 & 552.580 \\
& SD & 178.112 & 215.256 & 273.280 & 289.056 & 271.821 \\
& $95 \% \mathrm{Cl}$ & $727.32-837.54$ & $814.87-951.34$ & $638.83-825.88$ & $535.01-721.85$ & $463.25-653.23$ \\
Group Lf & Mean & 797.241 & 890.000 & 712.140 & 566.150 & 486.800 \\
& SD & 199.372 & 165.901 & 202.052 & 131.699 & 181.216 \\
& $95 \% \mathrm{Cl}$ & $723.46-868.61$ & $826.7-949.25$ & $640.01-788.85$ & $513.86-616.53$ & $425.21-556.8$ \\
Group Bb & Mean & 851.250 & 895.517 & 707.590 & 567.590 & 532.220 \\
& SD & 211.946 & 225.730 & 223.442 & 135.330 & 170.166 \\
& $95 \% \mathrm{Cl}$ & $784.75-931.55$ & $813.82-984.11$ & $633.1-794.13$ & $516.13-622.4$ & $472.59-598.15$ \\
& $p$-value & 0.627 & 0.603 & 0.988 & 0.998 & 0.351 \\
\hline
\end{tabular}

of intervention $(p=0.015)$. For this period, in the Control group, $80 \%$ of infants showed a frequency of depositions between 1 and 3 times per day, in contrast with $57-59 \%$ of infants in the probiotic groups (Fig. 3). An interaction with the type of delivery was observed. Infants born by natural delivery had a higher risk of having lower frequency of faecal depositions when they were in the Lf or Bv group in comparison with infants from the Control group, whose risk was lower $(\mathrm{OR}=0.411$ for $\mathrm{Lf}$ group $p=0.011 ; \mathrm{OR}=0.404$ for group $\mathrm{Bv}, p=0.009$ ). However, for infants born by C-section, the opposite occurred. For infants born by $\mathrm{C}$-section, the odds of having stools more often was 3.07 and 1.66 times higher in the Lf and $\mathrm{Bb}$ groups than in the Control group $(p=0.002$ Lf vs. Control group; $p=0.022 \mathrm{Bb}$ vs. control group).

Faeces colour: yellow, green or grey colours were more likely to be observed at the beginning of the trial. As the trial progressed, the faeces colour was more likely brown. Brown colour was more likely to occur in infants from the Lf and $\mathrm{Bb}$ groups than in infants in the Control group $(\mathrm{OR}=1.595$ for Lf group, $\mathrm{p}=0.002$ vs. Control group; $\mathrm{OR}=1.639$ for $\mathrm{Bb}$ group, $p=0.001$ vs. Control group).

Stool consistency: the percentage of infants showing higher stool consistency increased with time $(p<0.001)$. No differences were observed between the Control group and $\mathrm{Bb}$ group $(p=0.270)$. However, the behaviour of infants in the Lf group changed with time $(\mathrm{p}=0.001)$, and while it was observed that the risk of having softer stools was 1.89 times lower in the Lf group than in the control group at the beginning of the study, after four months, this risk changed, and the odds of softer consistency was 1.6 times higher in the Lf group than in the Control group $(p=0.015)$.

Symptoms of gastrointestinal discomfort associated with the diet were evaluated. Infants born by $\mathrm{C}$-section had a higher risk of suffering from more flatulence in comparison with infants born by natural delivery $(\mathrm{OR}=$ 2.022; $p=0.038$ ). As the study progressed, the risk of suffering from flatulence decreased in all of the groups; however, for the Lf group, the decrease throughout the study was more pronounced $(\mathrm{OR}=0.658 ; \mathrm{p}=0.038)$. At

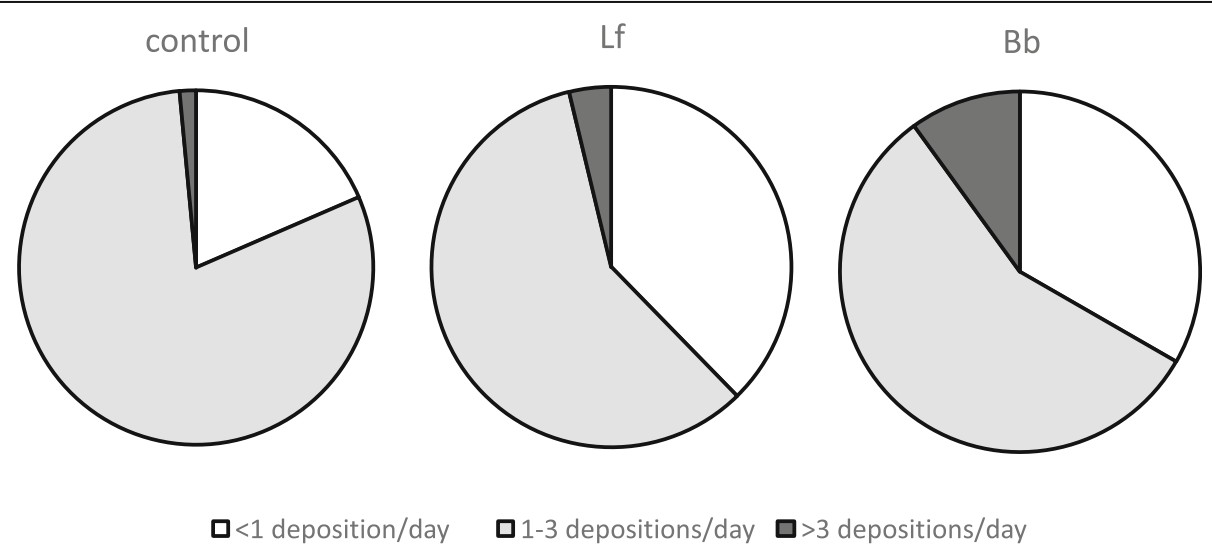

Fig. 3 Proportions in each group of infants showing $<1$ faecal deposition/day (white), 1-3 faecal depositions/day (grey) or $>3$ faecal depositions/day 
the beginning of the study and during the first two months, more than $70 \%$ of infants suffered from regurgitation, which was mild in most cases. As the study progressed over time, the frequency of regurgitation decreased to around 5\% at the end of intervention $(p=0.000)$. No differences were observed among groups.

Some variables related to the behaviour of infants were analysed. Data about the daily hours of crying were collected. In general, infants receiving B. breve CECT7263 had 1.7 times lower risk of long episodes of crying along the study than did infants in the Control group (OR = 0.569 CI 95\% 0.568-0.571; $p=0.001$ ). Because a symptom of infant colic is daily crying lasting more than $3 \mathrm{~h}$, the frequency of infants crying more than $3 \mathrm{~h}$ was analysed (Fig. 4). At the beginning of the study, approximately $16 \%$ of infants cried more than $3 \mathrm{~h} /$ day. At 6 weeks, a maximum percentage of $29 \%$ was observed in the Control group, versus $21 \%$ in the Lf group ( $p=$ $0.335)$ and $12 \%$ in the $\mathrm{Bb}$ group $(p=0.022)$. The frequency of infants suffering from infant colic symptoms decreased to below $2 \%$ at 4 months of age, with no differences between groups after that age.

Hours of sleep during the night were similar in all the groups. The total hours of sleep per day were similar between the $\mathrm{Bb}$ group and the Control group $(p=0.927)$. The behaviour of the Lf group was different compared to the Control group (OR $=0.457 ; p=$ 0.028), but the effect was dependent on the age of the infants $(p=0.001)$. At the beginning of the study, infants in the Lf group had lower odds of sleeping more hours per day, but, at the end of the study, they had higher odds $(\mathrm{OR}=2.828 ; p=0.007)$. No differences were found in the level of activity of infants upon waking ( $p=0.674$ for Lf vs. Control group and $p=0.420$ for $\mathrm{Bb}$ vs. Control group).

\section{Infant's health}

The most common infection during the first year of life of infants in this study was upper respiratory infections (83.4\% of infants suffered at least one event). No differences were detected among the groups in incidence of respiratory infections affecting the upper or lower tract (Table 5). However, for infections affecting the upper respiratory tract, the adjusted results from the multivariate model showed an effect of smoking habits of the mothers during pregnancy in the Control group. Thus, the incidence of upper respiratory tract infections was significantly higher in cases of smoking women (IRR = 1.996 CI 95\% 1.366-2.860; $p=0.000$ ). In cases of infants from smoking mothers, the incidence of these respiratory infections in infants in the Lf and $\mathrm{Bb}$ groups was significantly lower than the incidence in the Control group (IRR $=0.503$ CI 95\% 0.274-0.899 and $p=0.023$ for Lf group; IRR $=0.479 ;$ CI 95\% 0.269-0.844 and $p=0.011$ for $\mathrm{Bb}$ group). An effect of type of birth was also detected. In infants born by $\mathrm{C}$-section the incidence of upper respiratory infections was lower in Lf group than in control group (IRR $=0.492$; CI 95\% 0.294-0.815; $p=$ 0.006). In case of $\mathrm{Bb}$ group the effect did not reach to be statistically significant although a trend was observed (IRR = 0.630; CI 95\% 0.372-1.062; $p=0.084)$.

Regarding to gastrointestinal infections, 39\% of the infants suffered at least one event of diarrhoea. Logistic regression mixed model analysis showed a general increase in the risk of diarrhoea throughout the study $(p<0.001)$ and 2.5 times higher odds of diarrhoea in infants attending kindergarten $(p=0.005)$. No differences were detected in the incidence of diarrhoea between the $\mathrm{Bb}$ group and the Control group. However, the consumption of L. fermentum CECT5716 significantly reduced the incidence of diarrhoea by $44 \%$ in comparison with

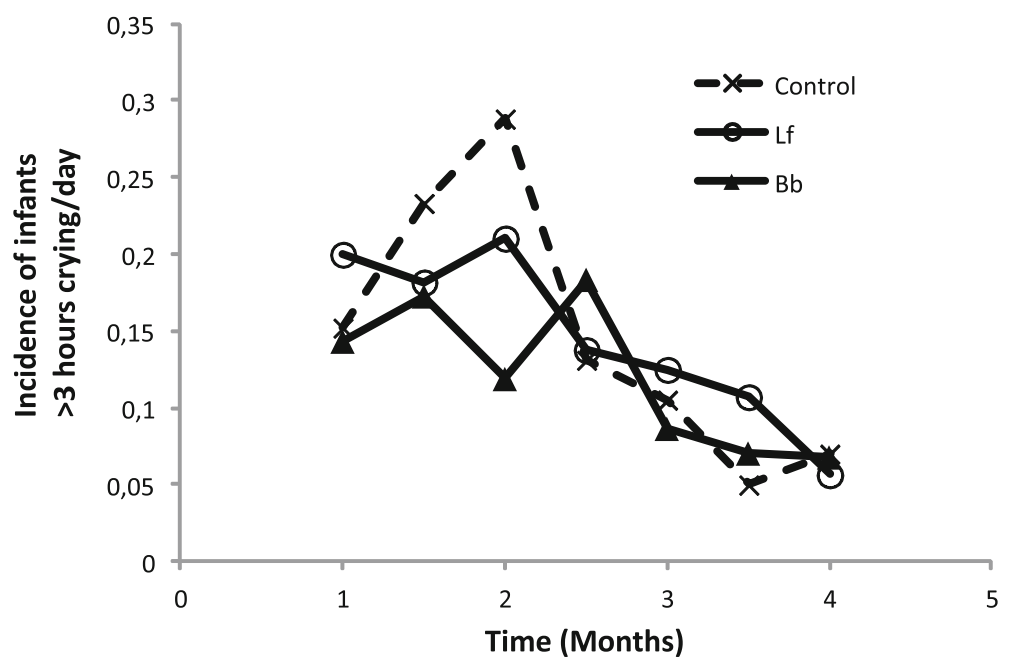

Fig. 4 Incidence of infant crying $>3 \mathrm{~h}$ per day 
Table 5 Incidence of infectious disease, febrile episodes and dermatitis during the intervention period

\begin{tabular}{|c|c|c|c|c|c|c|c|c|c|c|}
\hline & \multicolumn{3}{|c|}{ Number of events (N) } & \multicolumn{3}{|c|}{$\begin{array}{l}\text { Incidence Rate } \\
\text { (Standard Error) }\end{array}$} & \multicolumn{2}{|c|}{ Lf vs Control group } & \multicolumn{2}{|l|}{$\begin{array}{l}\text { Bb vs Control } \\
\text { group }\end{array}$} \\
\hline & $\begin{array}{l}\text { Control } \\
(61)\end{array}$ & $\begin{array}{l}\text { Lf group } \\
(65)\end{array}$ & $\begin{array}{l}\text { Bb group } \\
(63)\end{array}$ & Control & Lf group & $\overline{B b}$ group & $\begin{array}{l}\text { IRR } \\
(95 \% \mathrm{Cl})\end{array}$ & $\overline{p \text {-value }}$ & $\begin{array}{l}\text { IRR } \\
(95 \% \mathrm{Cl})\end{array}$ & $\overline{p \text {-value }}$ \\
\hline Diarrhoea $^{a}$ & 42 & 25 & 49 & $\begin{array}{l}0.689 \\
(0.106)\end{array}$ & $\begin{array}{l}0.385 \\
(0.077)\end{array}$ & $\begin{array}{l}0.778 \\
(0.113)\end{array}$ & $\begin{array}{l}0.559 \\
(0.326-0.938)\end{array}$ & 0.014 & $\begin{array}{l}1.129 \\
(0.745-1.777)\end{array}$ & 0.750 \\
\hline Upper tract & 146 & 168 & 132 & $\begin{array}{l}2.393 \\
(0.212)\end{array}$ & $\begin{array}{l}2.585 \\
(0.206)\end{array}$ & $\begin{array}{l}2.096 \\
(0.188)\end{array}$ & $\begin{array}{l}1.080 \\
(0.829-1.309)\end{array}$ & 0.673 & $\begin{array}{l}0.876 \\
(0.663-1.076)\end{array}$ & 0.223 \\
\hline Lower tract & 34 & 49 & 44 & $\begin{array}{l}0.557 \\
(0.101)\end{array}$ & $\begin{array}{l}0.754 \\
(0.108)\end{array}$ & $\begin{array}{l}0.700 \\
(0.107)\end{array}$ & $\begin{array}{l}1.354 \\
(0.814-2.054)\end{array}$ & 0.190 & $\begin{array}{l}1.257 \\
(0.756-1.953)\end{array}$ & 0.293 \\
\hline Conjunctivitis & 11 & 4 & 8 & $\begin{array}{l}0.180 \\
(0.054)\end{array}$ & $\begin{array}{l}0.062 \\
(0.031)\end{array}$ & $\begin{array}{l}0.127 \\
(0.045)\end{array}$ & $\begin{array}{l}0.344 \\
(0.080-1.170)\end{array}$ & 0.071 & $\begin{array}{l}0.705 \\
(0.246-1.922)\end{array}$ & 0.473 \\
\hline Otitis & 11 & 11 & 18 & $\begin{array}{l}0.180 \\
(0.054)\end{array}$ & $\begin{array}{l}0.169 \\
(0.051)\end{array}$ & $\begin{array}{l}0.286 \\
(0.067)\end{array}$ & $\begin{array}{l}0.939 \\
(0.369-2.387)\end{array}$ & 0.883 & $\begin{array}{l}1.589 \\
(0.709-3.712)\end{array}$ & 0.218 \\
\hline Urine Infection & 2 & 2 & 1 & $\begin{array}{l}0.033 \\
(0.023)\end{array}$ & $\begin{array}{l}0.031 \\
(0.022)\end{array}$ & $\begin{array}{l}0.016 \\
(0.016)\end{array}$ & $\begin{array}{l}0.940 \\
(0.069-13.149)\end{array}$ & 0.958 & $\begin{array}{l}0.485 \\
(0.008-9.300)\end{array}$ & 0.540 \\
\hline Fever & 32 & 28 & 27 & $\begin{array}{l}0.525 \\
(0.096)\end{array}$ & $\begin{array}{l}0.431 \\
(0.081)\end{array}$ & $\begin{array}{l}0.429 \\
(0.084)\end{array}$ & $\begin{array}{l}0.821 \\
(0.461-1.362)\end{array}$ & 0.193 & $\begin{array}{l}0.817 \\
(0.463-1.383)\end{array}$ & 0.172 \\
\hline Dermatitis & 7 & 2 & 7 & $\begin{array}{l}0.115 \\
(0.043)\end{array}$ & $\begin{array}{l}0.031 \\
(0.022)\end{array}$ & $\begin{array}{l}0.111 \\
(0.042)\end{array}$ & $\begin{array}{l}0.270 \\
(0.028-1.430)\end{array}$ & 0.105 & $\begin{array}{l}0.965 \\
(0.290-3.235)\end{array}$ & 0.947 \\
\hline
\end{tabular}

${ }^{a}$ Of the 42 diarrhea events in the control group, 19 occurred before 6 months and 23 in the period of 6 to 12 months. In the case of the Lf group, of the 25 diarrhea events 8 took place before 6 months and 17 in the period of 6 to 12 months

the Control group (IRR 0.559; CI 95\% 0.326-0.938; $p=$ 0.014) (Table 5). Analysis including the data of all infants, while they had not completed the study, showed similar results (IRR $=0.587$; CI 95\% 0.351-0.961; $p=$ $0.037)$. No differences were observed in the risks of having at least 1 event of diarrhoea $(\mathrm{OR}=0.86$; CI $95 \%$ $0.41-1.77 ; p=0.732$ ) but were observed in the risk of having more than 1 event of diarrhoea, which was 14 times lower in the Lf group than in the Control group $(\mathrm{OR}=0.07$; CI 95\% 0-0.54; $p=0.002)$. The beneficial effect of L. fermentum CECT5716 on diarrhoea was also observed in the duration of the events. The mean duration of diarrhoea in the Control group was 7.10 \pm 4.9 days (CI 95\% 5.25-8.95), while in the Lf group, the mean duration of diarrhoea was $4.55 \pm 3.6$ days (CI 95\% 2.956.14) $(p=0.044)$. No differences were observed in the duration of diarrhoea in the $\mathrm{Bb}$ group (6.24 \pm 4.7 days; CI 95\% 4.57-7.91; $p=0.482$ in comparison with the Control group).

No significant differences were observed in the incidence of other infectious diseases (otitis, conjunctivitis and urinary tract infections), febrile episodes and dermatitis (Table 5).

\section{Faecal microbiota}

Some of the most representative bacterial genera were studied (Table 6). The abundance of Lactobacillus in faeces was higher for the first months and decreased with time $(p=0.000)$. Infants in the Lf group had significantly higher values of Lactobacillus in their faeces in comparison to the Control group $(\mathrm{p}=0.000)$ and $\mathrm{Bb}$ group $(p=0.024)$. At 4 months of age, infants in the $\mathrm{Bb}$ group showed higher levels of Lactobacillus in their faeces $(p=0.000)$, but differences were not observed in later measurements. Regarding Bifidobacterium, a general increase over time was observed $(p=0.000)$. In the case of the $\mathrm{Bb}$ group, no differences were observed between bacterial load in faeces of infants in the $\mathrm{Bb}$ group and those of the Control group $(p=0.085)$. For the Lf group, a lower load of Bifidobacterium was observed at 4 months $(p=0.038)$, but no significant differences were observed at later times. A higher load of Bifidobacterium in faeces was related to a lower risk of diarrhoea $(\mathrm{OR}=$ 0.767 CI 95\% 0.608-0.976; $p=0.027$ ).

A general increase in Clostridium load in faeces was observed with time $(\mathrm{p}=0.000)$. A significant difference was observed between the $\mathrm{Bb}$ group and the Control group, with infants in the $\mathrm{Bb}$ group having a higher level of Clostridium in their faeces $(p=0.026)$. Clostridium load in infants attending kindergarten was significantly lower $(p=0.009)$, but it did not change the effect of the treatment. It was observed that Clostridium load in faeces was significantly associated with a reduction of the risk for dermatitis for all groups $(p=0.010)$, meaning infants with higher levels of Clostridium had a lower risk of developing dermatitis. With respect to Bacteroides, increasing values of bacteria with time were observed in all groups $(\mathrm{p}=0.000)$. Infants in the Lf group had higher values of Bacteroides than infants in the Control group $(p=0.044)$. A decrease in the load of Escherichia coli was also detected with time $(\mathrm{p}=0.000)$. Values of $E$. coli in faeces were comparable among the groups $(p=0.806$ 


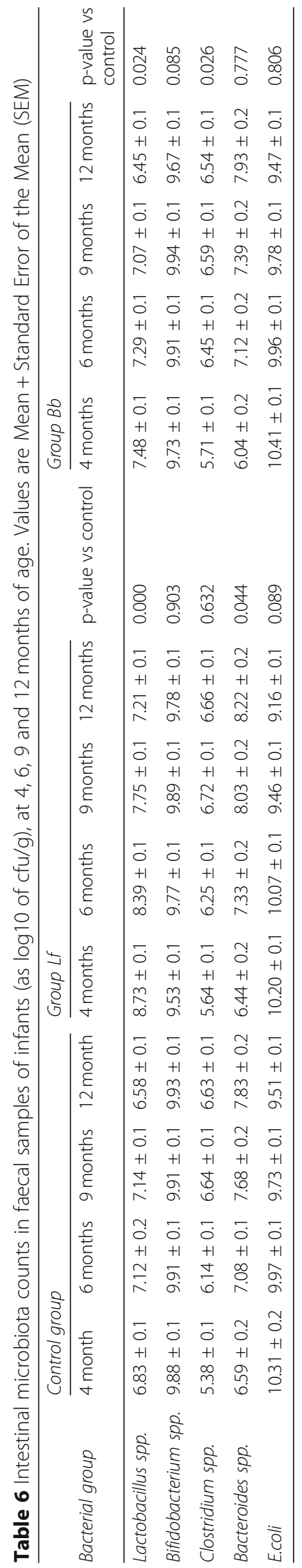


for the Control group vs. Bb group; $p=0.089$ for the Control group vs. Lf group).

\section{Discussion}

The effects and safety of the two probiotic strains originally isolated from breast milk have been studied in the present trial in infants. Determination of growth of infants is the single most valuable component of the clinical evaluation of an infant formula [28, 29]. The analysis of the curves of growth for weight, length and head circumference by age showed similar values for the three groups. Moreover, the values of three groups were comparable for the standards of growth based on healthy infants published by the World Health Organization [30], indicating the nutritional sufficiency and safety of the experimental formula. Although, in general, the growth of infants was similar in the three groups, at 4 months a higher length was observed in infants in the Lf group. However, the difference was not detectable in the measurements carried out in the subsequent months. In previous studies, a certain effect of $L$. fermentum CECT5716 on the length of infants who received the probiotic strain up to 6 months of age was also observed [12]. Although, the difference was not sustained, and the length of the children at 3 years of age was similar to a control group [13]. The effect was not observed in a third study performed in infants who received the probiotic strain from 6 to 12 months of age [14]. The effects of probiotic strains on growth of infants have been observed for some strains [31, 32]. It has been proposed that the activity of the bacteria on mucosal physiology might influence the absorption of nutrients, as well as metabolic and endocrine functions [12, 33]. Even so, more studies should be performed in order to investigate the mechanisms involved. Interestingly, it was observed that the negative effect on length of $\mathrm{C}$-section was counteracted by $L$. fermentum CECT5716 and B. breve CECT7263. C-section, which involves preventive antibiotic treatment for the woman, affects infant gut colonization [34]. It has been previously hypothesized that certain probiotics may prevent or attenuate the adverse effects of antibiotics on gut communities, thereby stabilizing gut integrity and improving the absorption of nutrients [33]. Therefore, the effects observed in our study might be related to the modulation of gut microbiota by the probiotic strains.

Continuing with the evaluation of the tolerance of the probiotic formula, the data regarding the daily intake of formula and the presentation of gastrointestinal symptoms, such as reflux, constipation or flatulence, demonstrated that both probiotic formulas were well tolerated.

Interestingly, during the evaluation of the behaviour of infants, it was detected that infants receiving the $\mathrm{Bb}$ formula had significantly lower risk of crying than did the control group. Infantile colic is a benign, self-limiting process in which a healthy infant has paroxysms of inconsolable crying. The standard diagnostic criteria is based in crying time more than three hours per day, more than three days per week, for longer than three weeks [35]. It affects approximately 10 to $40 \%$ of infants worldwide and peaks at around six weeks of age. Symptoms resolve usually by three to four months. In our study, a maximum percentage of infants crying more than $3 \mathrm{~h}$ /day was observed at 6 weeks (29\%); however, this percentage was reduced to $12 \%$ in the group receiving the Bifidobacterium strain. Although the cause of infantile colic has not been totally elucidated, alterations in faecal microflora, intolerance to cow's milk protein or lactose, gastrointestinal immaturity or inflammation, increased serotonin secretion, poor feeding technique, and even maternal smoking have been related [36]. In line with the role of the microbiota, some probiotic strains have been reported to reduce the crying time of infants suffering from infantile colic [37]. As the present study was performed with a generally healthy population, specific studies to evaluate the effect of B. breve CECT726 on infantile colic should be performed in order to corroborate the possible role of this strain in reducing the symptoms of this condition.

The most common infection during the first year of life in the infants of this study was upper respiratory infections. A beneficial effect was observed with both probiotic treatments in infants born from smoking mothers. This population, who are at a higher risk of suffering respiratory infections [38], showed lower rates of incidence in the groups consuming L. fermentum CECT5716 or B. breve CECT7163. A higher incidence of respiratory infections in infants born from smoking mothers has been related to the adverse effects of in utero smoke exposure on the infant's immune system [39-41]. Because Lactobacillus and Bifidobacterium are not common habitants of upper respiratory mucosa, it seems that the effect of the probiotic strains on the immune system might contribute to the observed effect. In this sense, L. fermentum CECT5716 was previously described to reinforce the immune response by enhancing both the innate and specific immune responses [42, 43]. Recent findings have highlighted important roles of gut microbiota on lung immunity [44] and certain probiotic treatments have shown efficacy in the prevention of respiratory infections and/or reduction in the severity of the infections [45, 46]. The effect of L. fermentum CECT5716 on upper respiratory infections in infants was also previously observed in a study performed in infants with a follow-on formula containing the Lactobacillus strain. In that study, the consumption of the probiotic formula was related to a reduction in the incidence rate of upper respiratory infections by $26 \%$ in comparison with the 
incidence in infants receiving a standard formula [14]. A limitation of our study is that the effect has been observed in infants born from smoking mothers, which is a small proportion of the infants of the study.

L. fermentum CECT5716 has also been related to significant reductions in the incidence rates of gastrointestinal infections [12, 14]. In our study, a reduction of $44 \%$ in the incidence of diarrhoea has been observed. A limitation of the study is that the sample size was calculated in order to detect differences in the weight gain of infants as a safety marker. The sample size needed to detect differences in the incidence of gastrointestinal infections would be higher. However, the value of the decrease in incidence is very similar to the $46 \%$ observed in the Maldonado study [14]. Therefore, the results of the present study corroborate previous ones, showing that, in a repetitive and consistent way, the administration of this strain to infants being fed formula protects them against gastrointestinal infections. Different mechanisms, such as the competitive phenomena, production of antibacterial compounds and improvement of the immune response, have been attributed to the antiinfectious activity of probiotics and concretely to $L$. fermentum CECT5716 [47]. The effect of the strain seems to primarily affect repetitive infections, supporting a probable role of the immune system. The consumption of the probiotic strain also reduced the duration of diarrhoea by approximately 2.5 days with respect to the control group. There is extensive literature regarding the efficacy of probiotics on the treatment of diarrhoea. A systematic review, which included 56 trials, concluded that probiotics reduced the duration of diarrhoea by a mean of one day $(24.76 \mathrm{~h}$; $95 \%$ confidence interval 15.9 to $33.6 \mathrm{~h} ; n=4555$ ); however, the size of the effect varied considerably among studies [48]. A larger difference in duration of diarrhoea has also been reported in another study performed in healthy infants receiving an infant formula containing a strain of Bifidobacterium longum [49]. More studies are needed to determine if probiotic use during childhood is a more efficient tool in reducing the severity of eventual diarrhoea than the treatment approach.

Regarding faecal microbiota, minor changes were associated with the probiotic treatments. As previously reported [14], the administration of L. fermentum CECT5716 was associated with an increase in the faecal load of lactobacilli. Moreover, a higher faecal load of Bacteroidetes was observed. On the other hand, intervention with $B$. breve CECT7263 did not affect the Bifidobacterium content in faeces. The concentration of Bifidobacterium in faeces is close to $10^{10} \mathrm{cfu} / \mathrm{g}, 3$ magnitudes of order higher than Lactobacillus. Since the daily ingestion of $B$. breve was between $7 \times 10^{8}$ and $1 \times 10^{9}$ cfus, it would be difficult to observe significant changes in the total load of Bifidobacterium in faeces. However, it has been previously reported that while changes in Bifidobacterium spp. load could not be observed after oral administration of an infant formula supplemented with another Bifidobacterium strain, B. animalis lactis ssp. lactis Bb12, the strain could be detected in the faeces of a high percentage of infants who received the probiotic formula [50]. Therefore, while B.breve CECT7263 did not induce a significant increase in faecal Bifidobacterium population, the strain, included as one more species in the total microbiota, is able to affect the intestinal and immune functions as supported by the observed effects on infant colic and respiratory infections. The microbiota analysis in our study has been restricted to specific bacterial groups. In order to better understand how these probiotic strains might influence the microbiota of infants, a more complete microbiota analysis should be performed.

\section{Conclusion}

Consumption of L.fermentum CECT5716 or B.breve CECT7263 during first year of life is well tolerated and safe. Additionally, beneficial effects of the strains consumption were observed. While $L$. fermentum CECT5716 stands out for its protective effects against gastrointestinal infections, B. breve CECT7263 stands out for its effects on the symptoms of infantile colic, which is probably related to its effect on intestinal function. Given that both strains are found naturally in breast milk and show beneficial activities that could complement each other, the combination of both strains in infant formulas could be used as a strategy to improve the health of formula-fed infants. Since this study was designed to demonstrate safety of the probiotic formulae, new clinical trials focused in each beneficial effect should be performed to confirm these results from the secondary outcomes.

\section{Abbreviations \\ Cl: Confidence Interval; IR: Incidence Rate; IRR: Incidence Rate Ratio; OR: Odd Ratio}

\section{Acknowledgements}

Authors wish to thank for their collaboration in the study to Llenalia García Fernández (SEPLIN, Soluciones Estadísticas -Granada, Spain-) for the statistical analysis of the data.

\footnotetext{
Authors' contributions

JM was the principal investigator of the study, design of the study, recruitment and follow up of the infants, interpretation of the results, review of the manuscript. MG-C: design of the study, recruitment and follow up of the infants, interpretation of the results, review of the manuscript. JAM-L: monitorization, data management. MRB, KF, RJ, IJB, VB, EP, IP: design of the study, recruitment and follow up of the infants, review the manuscript. ADV: analysis of fecal samples, CRF control and logistic. MO: design of the study, interpretation of the results, manuscript writer. All the authors has read and approved the last version of the manuscript.
} 


\section{Funding}

This work was funded by Biosearch Life supported by a grant from the Agency of Innovation and Development of Andalusia (IDEA-Spain), Cofinanced by European Regional Development Fund (EC). Project Tittle: "New applications of probiotic strains and derived compounds with biological activity (POSTBIO)" and partially funded by Lactalis-Puleva (Granada, Spain). Employees of Biosearch Life listed as authors contributed to the design of study, analysis of samples, interpretation of data and in writing the manuscript (described in Author's contribution).

\section{Availability of data and materials}

The datasets used and/or analysed during the current study are available from the corresponding author on reasonable request.

\section{Ethics approval and consent to participate}

This study was carried out according to the Helsinki declaration, and the protocol was approved by the Regional Ethics Committee of the Sistema Andaluz de Salud based in Seville (Spain). Infants were included in the study after informed written consent was obtained from the parents or caregivers.

\section{Consent for publication}

Not applicable.

\section{Competing interests}

JAM- $L, A D V$ and $M O$ are workers of Biosearch Life owner of the patent of Lactobacillus fermentum CECT5716 and Bifidobacterium breve CECT7263. The rest of authors declare that they have no competing interests.

\section{Author details}

${ }^{1}$ Pediatric Unit, University Hospital Virgen de las Nieves, Granada, Spain. ${ }^{2}$ Pediatric Department, University of Granada, Granada, Spain. ${ }^{3}$ Biosanitary Research Institute (IBS), Granada, Spain. ${ }^{4}$ Maternal and Child Health and Development Network (SAMID), Health Institute Carlos III, Madrid, Spain. ${ }^{5}$ Unit of Metabolism and Pediatric Research (IMIBIC), Reina Sofia University Hospital, University of Córdoba, Cordoba, Spain. ${ }^{6} \mathrm{CIBEROBN}$, Cordoba, Spain. ${ }^{7}$ Biosearch Life, Research Department, Granada, Spain. ${ }^{8}$ Pediatric Clinic Roquetas, Roquetas de Mar, Almería, Spain. ${ }^{9}$ Andalusian Health Service, Andalusia, Spain. ${ }^{10}$ Clinic "Cristo de la Salud" Albolote, Granada, Spain.

\section{Received: 28 August 2018 Accepted: 27 September 2019}

\section{Published online: 21 October 2019}

\section{References}

1. Fernández L, Langa S, Martín V, Maldonado A, Jiménez E, Martín R, Rodríguez JM. The human milk microbiota: origin and potential roles in health and disease. Pharmacol Res. 2013;69(1):1-10.

2. Martín R, Langa S, Reviriego C, Jiménez E, Marín ML, Xaus J, Fernández L, Rodríguez JM. Human milk is a source of lactic acid bacteria for the infant gut. J Pediatr. 2003;143(6):754-8.

3. Timmerman HM, Rutten NBMM, Boekhorst J, Saulnier DM, Kortman GAM, Contractor $\mathrm{N}$, et al. Intestinal colonisation patterns in breastfed and formulafed infants during the first 12 weeks of life reveal sequential microbiota signatures. Sci Rep. 2017;7(1):8327.

4. Arrieta MC, Stiemsma LT, Amenyogbe N, Brown EM, Finlay B. The intestinal microbiome in early life: health and disease. Front Immunol. 2014:5:427.

5. Laforest-Lapointe I, Arrieta MC. Patterns of early-life gut microbial colonization during human immune development: an ecological perspective. Front Immunol. 2017:8:788.

6. Gensollen T, lyer SS, Kasper DL, Blumberg RS. How colonization by microbiota in early life shapes the immune system. Science. 2016;352(6285): 539-44.

7. Ismail IH, Oppedisano F, Joseph SJ, Boyle RJ, Licciardi PV, Robins-Browne RM, Tang ML. Reduced gut microbial diversity in early life is associated with later development of eczema but not atopy in high-risk infants. Pediatr Allergy Immunol. 2012;23(7):674-81.

8. Russell SL, Finlay BB. The impact of gut microbes in allergic diseases. Curr Opin Gastroenterol. 2012;28(6):563-9.

9. Kostic AD, Gevers D, Siljander H, Vatanen T, Hyotylainen T, Hamalainen AM, et al. The dynamics of the human infant gut microbiome in development and in progression toward type 1 diabetes. Cell Host Microbe. 2015;17(2): 260-73.
10. Cenit MC, Olivares M, Codoñer-Franch P, Sanz Y. Intestinal microbiota and celiac disease: cause, consequence or co-evolution? Nutrients. 2015;7(8):6900-23.

11. Bajer L, Kverka M, Kostovcik M, Macinga P, Dvorak J, Stehlikova Z, et al. Distinct gut microbiota profiles in patients with primary sclerosing cholangitis and ulcerative colitis. World J Gastroenterol. 2017;23(25):4548-58.

12. Gil-Campos M, López MÁ, Rodriguez-Benítez MV, Romero J, Roncero I, Linares MD, et al. Lactobacillus fermentum CECT 5716 is safe and well tolerated in infants of 1-6 months of age: a randomized controlled trial. Pharmacol Res. 2012;65(2):231-8.

13. Maldonado-Lobón JA, Gil-Campos M, Maldonado J, López-Huertas E, FloresRojas K, Valero AD, et al. Long-term safety of early consumption of Lactobacillus fermentum CECT5716: A 3-year follow-up of a randomized controlled trial. Pharmacol Res. 2015;95-96:12-9.

14. Maldonado J, Cañabate F, Sempere L, Vela F, Sánchez AR, Narbona E, et al. Human milk probiotic Lactobacillus fermentum CECT5716 reduces the incidence of gastrointestinal and upper respiratory tract infections in infants. J Pediatr Gastroenterol Nutr. 2012;54(1):55-61.

15. Turroni F, Milani C, Duranti S, Ferrario C, Lugli GA, Mancabelli L, van Sinderen D, Ventura M. Bifidobacteria and the infant gut: an example of coevolution and natural selection. Cell Mol Life Sci. 2018;75(1):103-18.

16. Arboleya S, Watkins C, Stanton C, Ross RP. Gut Bifidobacteria populations in human health and aging. Front Microbiol. 2016;7:1204.

17. Low JSY, Soh SE, Lee YK, Kwek KYC, Holbrook JD, Van der Beek EM, et al. Ratio of Klebsiella/Bifidobacterium in early life correlates with later development of paediatric allergy. Benef Microbes. 2017;8(5):681-95.

18. Walker WA. Initial intestinal colonization in the human infant and immune homeostasis. Ann Nutr Metab. 2013;63(Suppl 2):8-15.

19. Braegger C, Chmielewska A, Decsi T, Kolacek S, Mihatsch W, Moreno L, et al. Supplementation of infant formula with probiotics and/or prebiotics: a systematic review and comment by the ESPGHAN committee on nutrition. J Pediatr Gastroenterol Nutr. 2011;52(2):238-50.

20. EFSA Panel on Dietetic Products, Nutrition and Allergies (NDA). Scientific Opinion on the essential composition of infant and follow-on Formulae. EFSA J. 2014;12(7):3760.

21. Räihä NC, Fazzolari-Nesci A, Cajozzo C, Puccio G, Monestier A, Moro G, et al. Whey predominant, whey modified infant formula with protein/energy ratio of $1.8 \mathrm{~g} / 100 \mathrm{kcal}$ : adequate and safe for term infants from birth to four months. J Pediatr Gastroenterol Nutr. 2002;35:275-81.

22. Koletzko B, von Kries R, Closa R, Escribano J, Scaglioni S, Giovannini M, et al. Lower protein in infant formula is associated with lower weight up to age two years: a randomized clinical trial. Am J Clin Nutr. 2009;89:1836-45.

23. Scientific Committee on Food. Report of the Scientific Committee on Food on the revision of essential requirements of infant formulae and follow-on formulae. SCF/CS/NUT/IF/65 2003, from http://ec.europa.eu/food/fs/sc/scf/ out199_en.pdf. Accessed 19 January 2018.

24. Lu K, Luo X, Chen PY. Sample size estimation for repeated measures analysis in randomized clinical trials with missing data. Int J Biostatistics. 2008;4(1). https://doi.org/10.2202/1557-4679.1098 (Article 9).

25. Kelley K, Maxwell SE. Sample Size for Multiple Regression: Obtaining Regression Coefficients That Are Accurate, Not Simply Significant. Psychol Methods. 2003;8(3):305-21

26. Agostoni C, Decsi T, Fewtrell M, Goulet O, Kolacek S, Koletzko B, et al. Complementary feeding: a commentary by the ESPGHAN committee on nutrition. J Pediatr Gastroenterol Nutr. 2008;46(1):99-110.

27. World Health Organization. Diarrhea (definition and sequelae). (WHO) Available from http://www.who.int/topics/diarrhoea/en/. Accesed 19 January 2018.

28. Agget P, Agostini C, Goulet O, Hernell O, Koletzko B, Lafeber H, et al. The nutritional and safety assessment of breast milk substitutes and other dietary products for infants: a commentary by de ESPGHAN committee on nutrition. J Pediatr Gastroenterol Nutr. 2001;32:256-8.

29. Agget $P$, Agostoni $C$, Axelsson I, Goulet $O$, Hernell $O$, Koletzko B, et al. Core data for nutrition trials in infants: a discussion document -a commentary by the ESPGHAN committee on nutrition. J Pediatr Gastroenterol Nutr. 2003;36:338-42.

30. WHO Multicentre Growth Reference Study Group. WHO child growth standards: length/height-for-age, weight-for-age, weight-for-length, weightfor-height and body mass index-for-age: methods and development. Geneva: World Health Organization; 2006. http://www.who.int/childgrowth/ standards/technical_report/en/. Accessed 19 January 2018

31. Szajewska H, Chmielewska A. Growth of infants fed formula supplemented with Bifidobacterium lactis Bb12 or Lactobacillus GG: a systematic review of randomized controlled trials. BMC Pediatr. 2013;13:185. 
32. Vendt $\mathrm{N}$, Grünberg $\mathrm{H}$, Tuure T, Malminiemi O, Wuolijoki E, Tillmann V, et al. Growth during the first 6 months of life in infants using formula enriched with Lactobacillus rhamnosus GG: double-blind, randomized trial. J Hum Nutr Diet. 2006;19(1):51-8.

33. Härtel C, Pagel J, Spiegler J, Buma J, Henneke P, Zemlin M, et al. Lactobacillus acidophilus/Bifidobacterium infantis probiotics are associated with increased growth of VLBWI among those exposed to antibiotics. Sci Rep. 2017;7(1):5633.

34. Stokholm J, Thorsen J, Chawes BL, Schjørring S, Krogfelt KA, Bønnelykke K, Bisgaard $\mathrm{H}$. Cesarean section changes neonatal gut colonization. J Allergy Clin Immunol. 2016;138(3):881-9.

35. Wessel MA, Cobb JC, Jackson EB, Harris GS Jr, Detwiler AC. Paroxysmal fussing in infancy, sometimes called colic. Pediatrics. 1954;14(5):421-35.

36. Anabrees J, Indrio F, Paes B, AIFaleh K. Probiotics for infantile colic: a systematic review. BMC Pediatr. 2013;13:186

37. Schreck Bird A, Gregory PJ, Jalloh MA, Risoldi Cochrane Z, Hein DJ. Probiotics for the treatment of infantile colic: a systematic review. J Pharm Pract. 2017;30(3):366-74.

38. Metzger MJ, Halperin AC, Manhart LE, Hawes SE. Association of maternal smoking during pregnancy with infant hospitalization and mortality due to infectious diseases. Pediatr Infect Dis J. 2013;32(1):e1-7.

39. Pachlopnik Schmid JM, Kuehni CE, Strippoli MP, Roiha HL, Pavlovic R, Latzin $P$, et al. Maternal tobacco smoking and decreased leukocytes, including dendritic cells, in neonates. Pediatr Res. 2007;61:462-6.

40. Mercelina-Roumans P, Breukers R, Ubachs J, van Wersch J. Hematological variables in cord blood of neonates of smoking and nonsmoking mothers. J Clin Epidemiol. 1996:49:449-54.

41. Noakes P, Hale J, Thomas R, Lane C, Devadason SG, Prescott SL. Maternal smoking is associated with impaired neonatal toll-like-receptor-mediated immune responses. Eur Respir J. 2006;28:721-9.

42. Díaz-Ropero MP, Martin R, Sierra S, Lara-Villoslada F, Rodríguez JM, Xaus J, Olivares M. Two Lactobacillus strains, isolated from breast milk, differently modulate the immune response. J Appl Microbiol. 2007;102:337-43.

43. Olivares M, Diaz-Ropero MP, Sierra S, Lara-Villoslada F, Fonolla J, Navas M, Rodriquez JM, Xaus J. Oral intake of Lactobacillus fermentum CECT5716 enhances the effect of influenza vaccination. Nutrition. 2007;23(3):254-60.

44. McAleer JP, Kolls JK. Contributions of the intestinal microbiome in lung immunity. Eur J Immunol. 2018;48(1):39-49.

45. Hao Q, Lu Z, Dong BR, Huang CQ, Wu T. Probiotics for preventing acute upper respiratory tract infections. Cochrane Database Syst Rev. 2011;(9): CD006895. https://doi.org/10.1002/14651858.CD006895.pub2.

46. Weizman Z. The role of probiotics and prebiotics in the prevention of infections in child day-care centres. Benef Microbes. 2015;6(2):181-3.

47. Olivares M, Díaz-Ropero MP, Martin R, Rodriquez JM, Xaus J. Antimicrobial potential of four Lactobacillus strains isolated from breast milk. J Appl Microbiol. 2006;101:72-9.

48. Allen SJ, Martinez EG, Gregorio GV, Dans LF. Probiotics for treating acute infectious diarrhoea. Cochrane Database Syst Rev. 2010;11. https://doi.org/ 10.1002/14651858.CD003048.pub3.

49. Chouraqui JP, Grathwohl D, Labaune JM, Hascoet JM, de Montgolfier Leclaire M, Giarre M, Steenhout P. Assessment of the safety, tolerance, and protective effect against diarrhea of infant formulas containing mixtures of probiotics or probiotics and prebiotics in a randomized controlled trial. Am J Clin Nutr. 2008:87:1365-73.

50. Baglatzi L, Gavrili S, Stamouli K, Zachaki S, Favre L, Pecquet S, et al. Effect of infant formula containing a low dose of the probiotic Bifidobacterium lactis CNCM I-3446 on immune and gut functions in c-section delivered babies: a pilot study. Clin Med Insights Pediatr. 2016;10:11-9.

\section{Publisher's Note}

Springer Nature remains neutral with regard to jurisdictional claims in published maps and institutional affiliations.

Ready to submit your research? Choose BMC and benefit from:

- fast, convenient online submission

- thorough peer review by experienced researchers in your field

- rapid publication on acceptance

- support for research data, including large and complex data types

- gold Open Access which fosters wider collaboration and increased citations

- maximum visibility for your research: over $100 \mathrm{M}$ website views per year

At BMC, research is always in progress.

Learn more biomedcentral.com/submissions 